\title{
Light and electron microscopic studies of the prostate gland of adult one humped camel (camelus dromedarius)
}

\author{
S. M. Soliman*, K. M. Mazher, A. H. Abdelrazek \\ Department of Cytology and Histology, Faculty of Veterinary Medicine, Beni-Suef University
}

\begin{abstract}
The present study aimed to clarify the light and electron microscopic structure of the prostate gland of mature (one-humped camels) during different seasons of the year. Glands of seventy-two mature healthy animals (5-7 years old) were collected from the Cairo slaughter house during one year, (6 samples each month) and prepared to be studied microscopically by the light and electron microscope. The prostate gland was found to be consisted of an external dorsal part dorsal to the neck of the bladder and an internal part situated in the submucosa of the prostatic urethra. During active season (winter and spring), the corpus prostate was enveloped by a thick fibromuscular capsule which sent septa, to divide the gland into lobules. The parenchyma formed of compound tubuloalveolar adenomeres. The alveoli and tubules were lined by high columnar cells and few basal ones. The acini appeared at different stages of secretory activity (synthesis, storage, secretion and exhaustion). Ultrastructurally, the acinar cells contained well developed rough endoplasmic reticulum (rER), numerous mitochondria and a variable number of secretory granules. The duct system began as central collecting sinuses lined by simple columnar secretory epithelium. The pars interna occurred in the submucosa of the prostatic urethra enveloped by a thick fibro-muscular band. The branched tubuloalveolar parenchyma contained adenomeres lined with simple cuboidal epithelium. During the inactive season (summer and autumn), the stroma showed a marked proliferation of the fibromuscular tissue on the expense of the parenchymatous tissue. The adenomeres became very small or even rudimentary with narrow lumina devoid of secretory materials. Marked reduction in the cytoplasmic organelles with a total absence of the secretory granules was also pronounced.
\end{abstract}

During the last few years, great efforts had been done to increase the productivity of farm animals including camels in order to meet the progressive needs of man. Camels were used for milk, bristles and meat production. In addition they were required for transportation across the desert. Some recent studies commented the possibility of milk and urine extracts of camels in controlling the carcinogenic cells and some viruses (Sharmanov et al., 1978). Due to the above mentioned reasons and others, camels attracted the attention of many authors to study its genital glands to treat fertility problems and to increase their live stocks. El-Wishy et al., (1972); Mosallam (1981); Badawy et al., (1982); Zaghloul et al., (1988); Emara, (1994); Ruba et al., (2005); Bhosle et al., (2006) studied the prostate gland in camel, bull and buffalo bull and recorded seasonal variations concerning the morphology and physiology of the gland. The gland exhibited an active form during winter and spring. During summer and autumn the gland becomes inactive both structurally and physiologically. According to these authors the prostate gland is an important organ in reproduction as it produces fructose, citric acid,

* Corresponding author. Tel.: +20 0167102575 ;

Fax: +20 0822327982

E-mail address: soliman@bsu.edu.eg

(Shehata M. Soliman) glycerol phosphoryl choline (GPC) and other chemicals required for the nutrition and viability of sperms.

Consequently, the present study aimed to give a complete histomorphological picture about the gland of the adult male one-humped camels all year around.

\section{Materials and methods}

Prostate glands of seventy-two mature healthy male camels (5-7 years old) from Cairo slaughterhouse were collected monthly along the period over one year, (6 samples each month). Specimens of about $0.5 \mathrm{~cm}$ thick from prostate were collected and immersed immediately in $10 \%$ buffered neutral formalin and Bouin's solution. Sections of 4-6 micrometers-thick were obtained and mounted onto glass slide then stained with Harris Hematoxylin \& Eosin, Gomori's reticulin method, Crossmon's trichrome stain and Periodic acid schiff technique (PAS) as outlined by (Bancroft and Gamble, 2008).

In addition, twelve samples were prefixed in 4\%glutraldhyde in phosphate buffer solution (PH 7.4) at room temperature (Hayat, 1986) before they were post-fixed in $1 \%$ osmium tetroxide in phosphate buffer then embedded resin blocks. 
Ultra-thin sections $50-60 \mathrm{~nm}$ thick of the selected areas were mounted on copper grids and contrasted with $5 \%$ uranyl acetate followed by lead citrate (Reynolds, 1963), then examined by Joel transmission electron microscope at $100 \mathrm{KV}$ in the national institute of tumors, Cairo, Egypt.

\section{Results}

The mass reading of the histological samples of the camel's prostate collected monthly along a period of one year revealed both active and inactive forms. The active form was recorded during winter and spring (the rutting season), while the inactive form appeared in summer and autumn (the non-rutting season). Therefore, the findings were described and discussed in the two previously-mentioned forms.

Anatomically, the prostate glands of camels were consisted of an external part and internal part. The external one was discoid in shape and present at the dorsal aspect of the urethra over the neck of the urinary bladder. Its caudal third was connected to the prostatic urethra while the cranial two thirds were free. The internal part was situated in the sub mucosa of the prostatic urethra and continued with the glands present in the wall of the pelvic urethra (urethral glands).

During the active season (winter and spring).

Pars Externa. Glands collected from camels slaughtered during winter and spring appeared to be enveloped by a thick double-layered connective tissue capsule. The external layer was fibrovascular and the internal one was mainly fibromuscular in nature. It contained longitudinal bundles of collagen and smooth muscle fibers. In addition, a number of fibromuscular septa were originated from the inner capsular layer to divide the gland into lobules (Fig.1). A network of reticular fibers was recorded in the capsule, in the septa and to agreat extends around the secretory acini (Fig. 2). A positive PAS reaction was noticed in the stromal elements of the gland (Fig. 3).

The parenchyma of the pars externa was found to be cuts of the secretory acini and the duct system. Both were organized to form a compound tubulo-alveolar gland. The secretory acini were lined by high columnar cells and short few basal ones. The columnar cells appeared in different stages of secretory activity. Synthesis, storage, secretion and exhaustion stages could be demonstrated and described. During the stage of synthesis and storage, the acinar cells were found to be high columnar with spherical, basal and vesicular nuclei. The cytoplasm appeared vacuolated and finely granular with an apical acidophilia. The lumen became very narrow or nearly obliterated in some of them (Fig. 4).Ultrastructurally, the columnar cells showed euchromatic nuclei and the cytoplasm contained well-developed organelles as rough endoplasmic reticulum (rER), secretory granules and mitochondria.Inclusions in the form of secretory granules were recorded mainly in the apical part of the cell (Fig. 5). Also a well-developed multivesicular body together and few lipoid vacuoles could be observed.

During the secretory stage, the acinar cells were still columnar with basal, spherical and vesicular nuclei but the cytoplasm became less vacuolated and the apical part was more acidophilic (Fig. 6). Some bleb-like protrusions from the apical parts could be noticed during this stage.

The exhausted acini were characterized by being larger, wider and surrounded by lower epithelium. The lining cells had lost their apical parts and became low columnar to high cuboidal. The cytoplasm became less vacuolated and highly acidophilic. The secretory materials were collected in the wider lumina as an acidophilic homogenous mass (Fig.7). In electromicrograph, the cytoplasm of the exhausted cells showed a perinuclear network of a well-developed rough endoplasmic reticulum (rER), basal rounded mitochondria, numerous free ribosomes and few numbers of secretory granules. The nuclei were usually euchromatic (Fig. 8).

Between the acinar cells, there were a number of basal cells which appeared pyramidal to oval in shape with spherical nuclei and an acidophilic cytoplasm (Fig. 4, 6). The cells showed in EM an electron dense cytoplasm containing lipid vacuoles, occasionally secretory granules and heterochromatic nuclei (Fig. 5).

Actively secreting acini, whether synthesing, storing or exhausted, were similar regarding the presence of myoepthelial cells whose nuclei were located in a scant amount of fibrillar cytoplasm (Figs. 4, 6, 7)

The duct system began in the central part of the lobules. It lied between the secretory acini in the form of central collecting sinuses. They were lined by simple columnar secretory epithelium rested on a dense layer of fibrous tissue (Fig. 9). The cells, as the secretory ones showed a positive PAS reactivity especially in the apical cytoplasm. Electron microscopically, the cells showed an extensive network of well developed rough endoplasmic reticulum (rER), mitochondria, a number of lipid vacuoles and 

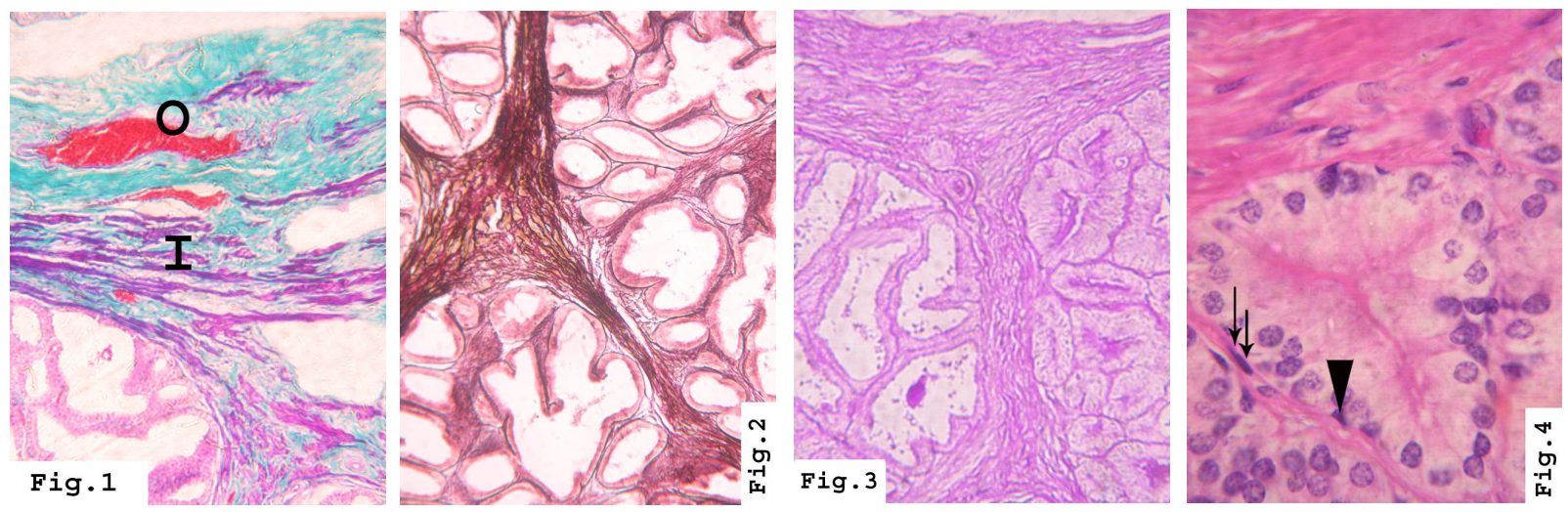

Fig.(1): A photomicrograph of the pars externa of the prostate gland of camel during the active season showing 2 parts of the capsule, an outer loose more vascular part ( $(0)$ and an inner fibro muscular part (I). Note the septa that arised from the capsule. Crossmon's trichrome stain, X100.

Fig. (2): A section through the pars externa of the prostate gland of camel during the active season showing network of reticular fibers in the septa and some strands around the secretory acini. Gomori's reticulin stain, X100.

Fig. (3): A section through the pars externa of the prostate gland of camel during the active season showing a PAS reaction in the capsule and in the septa. Note, that the apical part of secretory cells, luminal contents and basement membrane showed also positive reaction while the remaining part reacted moderately. PAS reaction X100.

Fig. (4): A high magnification of the one of the camel's prostatic acini whose highly active secretory cells nearly obliterate the acinar lumen. Note the basal cells (arrow head) and the myoepithelial cells (double arrow). H\&E stain, X1000.

some secretory granules. The lumen of the sinus might contained a secretory material (Fig. 10).

Pars interna. The pars interna was enveloped by a thick fibro-muscular tissue separating it from the pars externa. Fibro-muscular septa arised and divided the gland into small lobules (Fig. 11). Both the capsule and the septa were intermingled with few reticular and elastic fibers. The fibrous stroma was found to be reacted with PAS (Fig. 12).

The parenchyma of the gland was organized to form a branched tubulo-alveolar structure. The secretory units were lined with simple cuboidal epithelium. The cells showed central, spherical and vesicular nuclei and vacuolated cytoplasm with apical acidophilia. The acinar lumen might contain masses of acidophilic secretory material (Fig. 13). The later reacted moderately to PAS while the surrounding cells showed a very weak reaction (Fig. 12).

During the inactive season (summer and autumn). In the months of summer and autumn, the gland was found to be less or non-active, a finding which was coincided with the nonrutting season.

Pars externa. The stroma of the pars externa showed a marked increase of the fibromuscular tissue on the expense of the parenchyma which showed very small lobules (Fig. 14). On the other hand, the reticular and the elastic fibers remained few without any change.The fibrous stroma reacted moderately with PAS (Fig. 15).

The parenchyma of the pars externa was reduced in size as the secretory acini became rudimentary. The lumina were narrow and free from any secretory material. The epithelial lining of the acini became low cuboidal cells with flattened or elongated basal nuclei and their cytoplasm became slightly acidophilic and non vacuolated (Fig. 16). The cells reacted-weakly with the PAS technique (Fig. 15). Ultrastructure pictures of the cell showed a marked reduction in the number and marked disintegration of the cytoplasmic organelles. Also, the cytoplasm was devoid of any secretory granule and filled with numerous cytoplasmic vacuoles (Fig. 17).

The lining epithelium of the collecting sinuses became flat or low cuboidal cells showing no secretory activity. The cells reacted very weakly with the PAS technique (Fig. 15).

Pars interna. During the period of inactivity, the pars interna also showed a marked increase in the connective tissue stroma and the glandular tissue was represented by little groups of isolated small collapsed acini and excretory ductules. The secretory material was totally absent (Fig. 18).

\section{Discussion}

The activity of the gonads and the activity of their accessory glands were found to be influenced directly or indirectly by some vital factors as hereditary, ambient temperature, photoperiod and nutrition. Furthermore, the reproductive cycle was regulated by the interaction between the C.N.S, the pituitary gland and the gonads. The hypothalamus under the control of C.N.S controlled the secretion of gonadotropins by releasing regulating substances. The latter released or reduced the hormones of the pituitary gland according to the species of the animal (Bravo et al., 2000). 

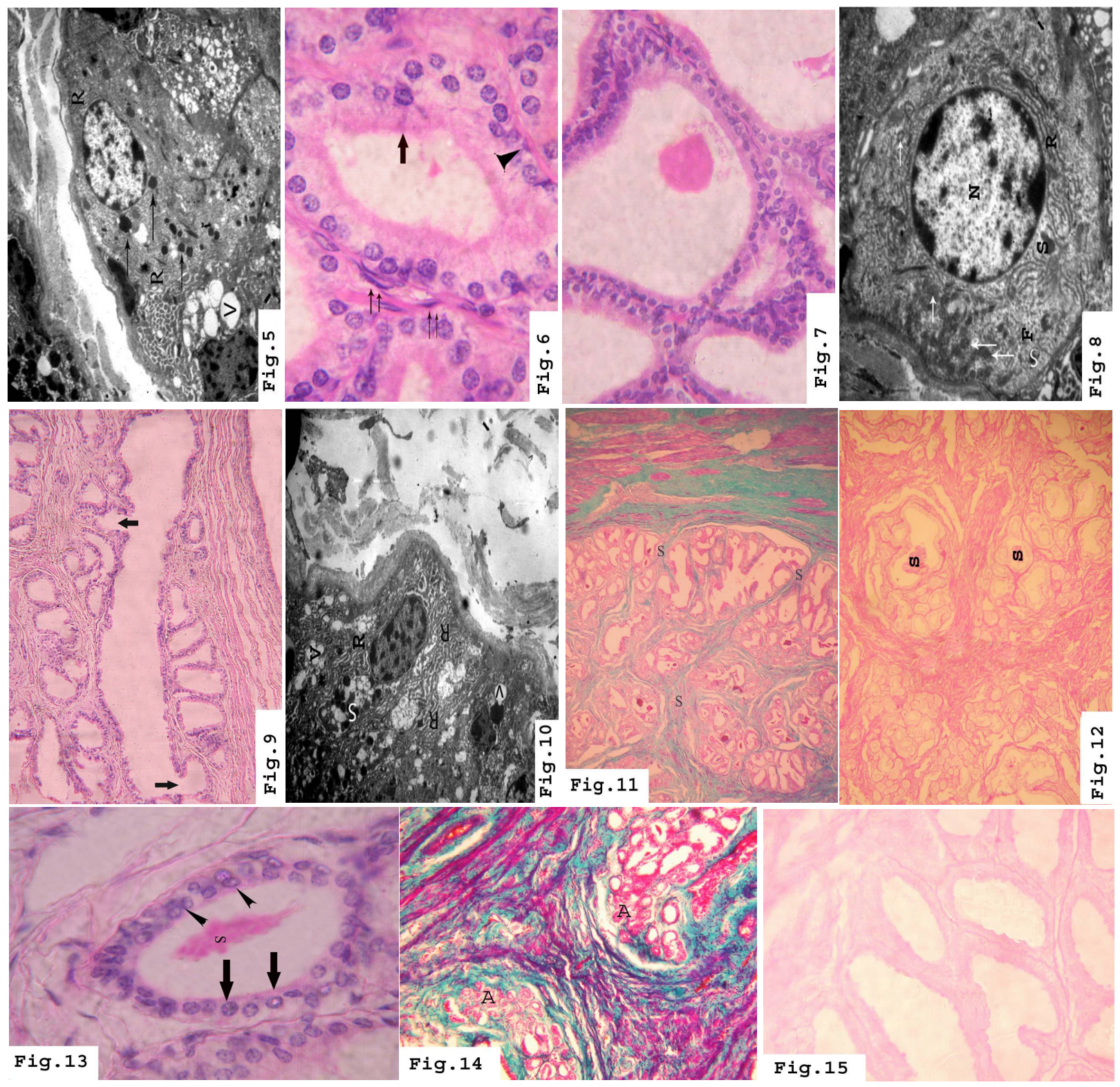

Fig.(5): An electron micrograph of an acinar cell (in synthesis stage) of pars externa of camel's prostate during active season showing euchromatic nucleus, secretory granules (arrow)and well-developed rough endoplasmic reticulum (R). Note one of the basal cells which was electron dense and its cytoplasm contained lipid vacuoles (V). Uranyl acetate and lead citrate stain, X1400.

Fig.(6): A higher magnification of parenchyma of pars externa of camel's prostate showing the high columnar lining epithelial cells with their vacuolated cytoplasm and more acidophilic apical part (arrow). Note the basal cells (arrow head) and myoepithelial cells (double arrows) surrounding the acinus. H\&E stain, X1000.

Fig. (7): A photomicrograph of the pars externa of the prostate gland of camel during the exhausted stage. The cells appeared low and lumina were wide. Note acidophilic homogenous secretory materials. H\&E stain, X400.

Fig.(8): An electron micrograph of a lining cell of an exhausted acinus of camel's external prostate during the active season showing a central oval euchromatic nucleus $(\mathrm{N})$, well-developed perinuclear $\operatorname{rER}(\mathrm{R})$, rounded mitochondria (arrow), secretory granules (S) and numerous free ribosomes (F).Uranyl acetate and lead citrate stain,X2700.

Fig. (9): A photomicrograph of the pars externa of the prostate gland of camel during the active season showing a longitudinal central collecting duct lined with columnar cells. Note that some of the acini open directly into the duct (arrow). H\&E stain, X100. Fig.(10): An electron micrograph of collecting duct cell of the pars externa of camel's prostate during the active season showing an extensive network of $r E R(R)$, lipid vacuoles $(V)$ and some secretory granules (S). Uranyl acetate and lead citrate stain, X1400.

Fig. (11): A photomicrograph of the internal prostate of the camel showing the fibromuscular stroma; capsule and septa(S) dividing the gland into several lobules. Crossmon's trichrome stain, $\mathrm{X100}$.

Fig. (12): A photomicrograph of the internal prostate of the camel during active season showing a weak PAS reaction in the fibrous stroma and in the basal lamina of secretory units. Note that the parenchyma of the gland, also, gave a weak reaction. The secretion (S) in the lumen reacted moderately, PAS technique, X100.

Fig. (13) Magnifies of secretory acinus of the camel's internal prostate during the active season showing simple cuboidal lining epithelium (arrow) stratified cuboidal (arrow heads) might be observed in some areas. Note the intra luminal acidophilic secretory material (S). H\&E stain, X1000.

Fig.(14): A section through the pars externa of the camel's prostate during the inactive season showing a marked increase of the fibromuscular tissue and the alveoli (A) became rudimentary and non functional. Crossmon's trichrome stain, X100.

Fig. (15): A photomicrograph of the parenchyma of the pars externa of the camel's prostate during the inactive season showing a very weak PAS reaction in the acini and in the connective tissue stroma. PAS reaction, $\mathrm{X200.}$ 

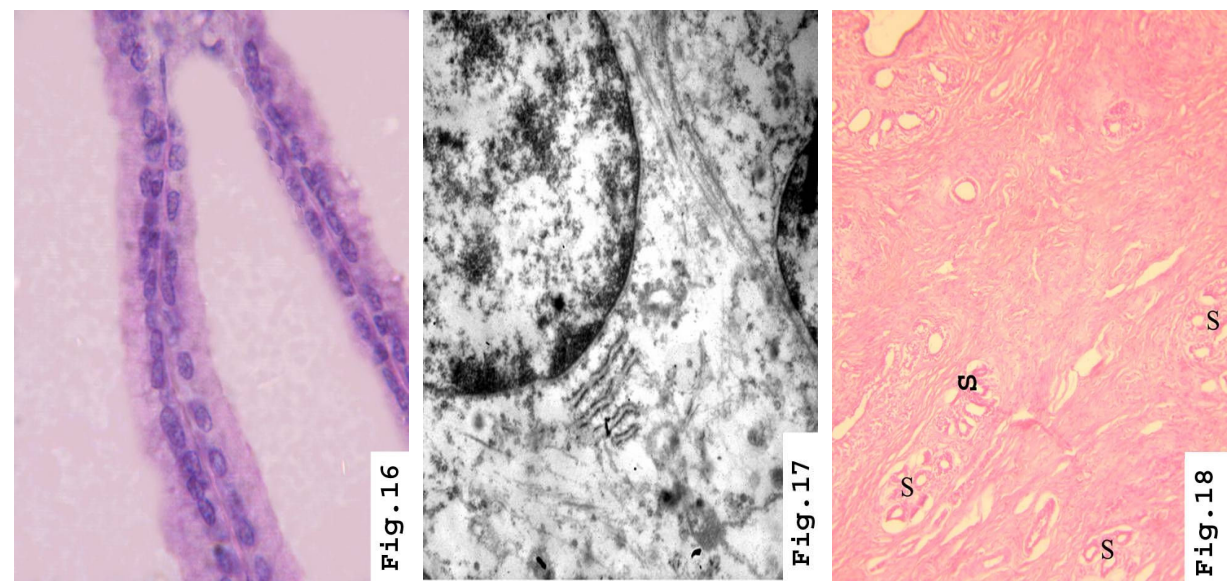

Fig. (16): A photomicrograph of the parenchyma of the pars externa of the camel's prostate during the inactive season showing low cuboidal lining epithelial cells. The nuclei were flattened basally situated. The cytoplasm was slightly acidophilic and non vacuolated. H\&E stain, X1000.

Fig.(17): An electron microgragph of an acinar cell of the pars externa of the camel's prostate during the inactive season showing a marked reduction of the cytoplasmic organelles . Uranyl acetate and lead citrate stain, X7000.

Fig.(18): A photomicrograph of the internal prostate of the camel during the inactive season showing a marked increase of the connective tissue stroma on the expense of the secretory units (S) which became isolated small collapsed acini. H\&E stain, X40.

Camels in Egypt were one of the farm animals whose reproductive activity was found to occur during winter and spring (rutting season) while during summer and autumn these activities were reduced or completely disappeared (non-rutting season), (Abdel-Raouf et al., 1975). During rutting and non-rutting seasons, significant changes could be detected in the behavior of the animals, in the quantities of hormones related to reproduction, in the gonads and, also, in the accessory genital glands. Seminal plasma was of great biochemical interest as it contained some organic compounds as fructose, citric acid, sorbitol, glyceryl phosphoryl choline and ergothionine which were not found elsewhere in the body in such high concentration. These substances were produced by the various accessory glands in response to testosterone, since thy disappeared from the seminal plasma after castration and reappeared after testosterone injections (White, 1974). Reproductive failure may be associated with defective seminal quality, accessory genital glands, abnormalities or improper management of the semen required for artificial insemination. Measurements of seminal characteristics reflects the functions of the testes, the excurrent ducts and the accessory genital glands

Owing to the above mentioned facts, structure of the accessory genital glands (especially prostate gland) by the light microscope, electron microscope and some available histochemical methods seemed to be very important in an animal which received little attention in literature.

Criteria of evaluation of the active and nonactive phenomena was the size of the gland, degree of development of the stroma and the parenchyma, size and shape of adenomeres, height of the cells, nature of the cytoplasm and the nucleus, content of the cell of neutral and acid mucopolyscharides and the degree of the developing cytoplasmic organelles in electron micrograph.

It is generally accepted that the prostate glands of camels were formed of a discoid external part over the neck of the urinary bladder and an internal part occupied the submucosa of the prostatic urethra (El-Wishy et al., 1972; Ali et al., 1978; Mosallam, 1981; Badawy et al., 1982; Nasr and Moustafa, 1988; Skidmore and Adams, 2000).

During the active season the corpus prostate was found to be well-developed. Being surrounded by a bilayered capsule; an outer looser part and an inner fibromuscular part. Similar findings were, also, observed in many domestic animals (Ali et al., 1978; Mosallam, 1981: Nasr and Moustafa, 1988; Emara, 1994; Sudhakar, 2005; Ruba et al., 2005). In bucks, Yao and Orson, (1954) decided that the capsule was of fibroelastic type. As mentioned by many authors, the fibromuscular stroma acted as a protective coat for the gland and supported the pathway of blood and lymph vessels and also the execratory duct system (AbdEl-Ghafar, 1988; Hafez, 1993; Marei et al., 2004).

As mentioned by Mosallam, (1981); Emara, (1994) the prostatic stroma was found to contain an extensive network of reticular fibers between the parenchymatous elements.

There was a general agreement that the prostatic parenchyma of many animal species was formed of a compound tubuloalveolar gland. 
This was the findings (El-Wishy et al., 1972; Ali et al., 1978; Mosallam, 1981; Badawy et al., 1982; Nasr and Moustafa, 1988; Emara, 1994; Sakairi et al., 2003: Marei et al., 2004; Sudhakar, 2005). In dogs, highly enfolded acini with prominent intraluminal ridges were recorded by Ruba et al., (2005), findings which could not be met in camels.

The secretory acini of the corpus prostate of the camels were found to be lined by columnar cells at different stages of secretory activities as recorded by El-Wishy et al., (1972); Ali et al., (1978); Mosallam, (1981); Badawy et al., (1982); AbdEl-Ghafar, (1988); Nasr and Moustafa, (1988); Hafez, (1993); Bhosle et al., (2006).

The present study showed in the E.M. electron dense granules accumulated in the apical of the cytoplasm. The vacuolation of the cytoplasm was attributed to the presence of lipid vacuoles and multivesicular bodies (Silvana et al., 2006; Wellerson et al., 2008). Bhosle et al., in 2006 explained the presence of multivesicular bodies as metabolic byproducts during the synthesis process.

The exhausted acini in sections prepared from camels during the rutting season appeared larger, wider and lined by low columnar to cuboidal cells. Ali et al., (1978) supported our observation by finding that the cells gave their secretion by losing their apical parts. The apocrinally lost parts of the cells were seen accumulated in some of the alveoli of the camels and these of rats (Sylwia et al., 2006).

The prostatic acinar cells of the studied camels showed a strong PAS reaction in the apical parts of the cell as well as the luminal contents. Findings which were recorded by Robert et al., (1969); Ali et al., (1976); Mosallam, (1981); Nasr and Moustafa, (1988); Bhosle et al., (2006). The authors attributed the PAS positive reaction to the presence of neutral mucopolysaccharide. Alcianophilia of the acinar cells of bucks which was recorded by Marei et al., (2004) disagreed with the findings in the camel's acini. A negative alcianophilic reaction was noticed, also, by Mosallam, (1981).

The prostatic acini of camels showed pyramidal basal cells with dark rounded nuclei and acidophilic lipid-containing cytoplasm. Identical cells were recorded by Timmes et al., (1976); Aly et al., (1991). The latter added that the presence of lipid vacuoles and some secretory granules indicated a limited role of these cells in secretion. It might be suggested that the basal cell were the precursors of the acinar columnar epithelium (Mao and Angrist, 1966; El-Alfy et al., 2000).

The duct system of the corpus prostate began as central collecting sinuses lined by simple columnar secretory epithelium. E.M. studies of the cells showed a network of well-developed rough endoplasmic reticulum, mitochondria, a number of lipid vacuoles together with some secretory granules. Ali et al., (1978) added that the collecting sinuses cells played a considerable role in the secretion as their cytoplasmic features were prepared for this function. The sequences of the interlobular ducts, which were lined with simple then stratified epithelia, before changing into transitional epithelium before opening into the urethra was also recorded by Ali et al., (1978); Mosallam, (1981).

Among most histologists, there was a general agreement that the internal part of prostate glands of camels was much smaller and had a lesser activity than that of the pars externa (Ali et al., 1978; Mosallam, 1981; Badawy et al., 1982). The part, in general, was found to similar to that of bulls (Robert et al., 1969). It appeared as small lobules disseminated in the propria submucosa of the prostatic urethra and enveloped by a thick fibromuscular coat derived from the urethral submucosa. Regarding the arrangement of the acini and the ducts, the part was seemed to be branched tubuloalveolar in type. The tubuloalveolar type of the gland was, also, recorded by Mosallam, (1981); Moussa et al., (1983); Emara, (1994); Bhosle et al., (2006). Branched tubules, however, were described by Yao and Orson, (1954) and a compound tubular conFiguration was described by Nicaise et al., (1991).

Close examination of the secretory units of camels revealed that they were lined by cuboidal cells, findings which were mentioned by Mosallam, (1981). However, other types of epithelia were demonstrated in the glands of other species; tall columnar and cuboidal cells (Moussa et al., 1983; Emara, 1994) or pseudostratified epithelium (Nicaise et al., 1991). In 2006, Bhosle et al., attributed the variation between the columnar and cuboidal cells into the different phases of secretory activity. At the E.M. level it had been found that these cells contained electron dense secretory granules as well as well-developed organelles which were taken by the authors as a sign of secretory activity. The duct system began by central collecting sinuses within the lobule lined 
by cuboidal secretory epithelium. Interlobular ducts lined with stratified epithelium then terminal ducts coated by transitional type were recorded and, also, were explained by Mosallam, (1981); Emara, (1994)

The accessory genital glands were testosterone dependant organs. They became well-developed and actively-secreting when the levels of the androgenic hormones were increased in the blood in the rutting season. During the non-rutting season, when the level of the hormones was declined to a minimum, the glands were regressed temporary before they resumed their functional activity during the subsequent rutting season.

During summer and autumn, all accessory glands behaved similarly. They became smaller in size and their products were greatly reduced and not stopped at all. Further examination of the glands revealed that the parenchyma was greatly reduced in size and structure and the interacinar and covering stroma were greatly increased so that one can said that the fibrous stroma was increased on the expense of the parenchyma (or the gland become more fibrous less cellular in nature). The findings were found to be the same in the prostate, bulbourethral, urethral and ampullary glands. Therefore, the changes would be discussed, in general, for all.

During the period of inactivity, a voluminous proliferation of the fibromuscular stroma (capsule and septa) on the expense of the parenchymatous tissue. The stromal elements became well-developed and thick. This was the findings of Badawy et al., (1982); Andrewa and Tam, (1984); Emara, (1994). It seemed that the fibroblasts in situ were sensitive to the hormone level. They became very active during the nonrutting season and maintained a minimal activity during the rutting season when the level of hormones was high. The hormone /cells relationship could be considered inversely-proportional.

The regressed growth and activity of acini, however, were studied at 3 levels of examination, L.M., E.M. and histochemical contents.

In microscopical slides, it had been found that the acini were greatly reduced in size and number, their lumina were small or even collapsed and the surrounding cells were low, of less acidophilic non-vacuolated cytoplasm and the cell boundaries became less conspicuous. Nearly the same L.M. pictures of cells were noticed to be the predominant in all glands studied and also in the related farm animals by different authors (El-Wishy et al., 1972; Ali et al., 1978; Mosallam, 1981; Badawy et al., 1982).

When seen in the E.M., the cells showed a great reduction in the organelles responsible for the synthesis and secretion of the gland. There was the least number of organelles and the demonstrated ones were ill-developed. The organelles which were affected by the low androgenic hormones during the non-rutting season were the rough endoplasmic reticulum and the mitochondria. All these criteria together with the demonstration of some lipoid inclusions and multivesicular cysts in some of the cells suggested in vitro signs of decreased activity (Aly et al., 1991; Marei et al., 2004; Badia et al., 2006).

In sections stained with PAS to indicate the activity of the cells to secrete neutral and/or acid mucopolysacharides, it have indicated that both alveolar and sinuses cells reacted negatively or even weakly suggesting their inability to synthesis such carbohydrates. The weak reaction could be attributed to the carbohydrate content of cells as one of basic structure of their cytoplasm and not a secretory product (Moussa et al., 1983).

\section{References}

Abdel-Ghafar, A.E. (1988): Morphological and histo chemical studies on the male genital organs of camels. M. V. Sc. Thesis., Zagazig Univ., Benha branch, Egypt.

Abdel-Raouf, M.; Fath El-Bab, M.R. and Owaida, M.M., (1975): Studies on reproduction in camels (Camelus dromedarius) Morphology of the testis in relation to age and season. J. Reprod. Fertil., 43:109-116.

Ali, H.A.; Tingari, M.D. and Moniem, K.A. (1978):On the morphology of the accessory male genital glands and histochemistry of the ampulla ductus deferentis of the camel (camelus dromedarius ) J. Anat., 122 (2): 277-292

Aly, B. A.E.; Abdo, M.S. and Khabir, A. (1991): The fine structure of the camel prostate. Anat. Anz, Jena., 172:223229

Andrewa, S. and Tam, W.H. (1984): Ultrastructural changes in the prostate gland of a seasonally breeding mammal, the grey squirrel (Sciuruscaro linensis Gmelin).J. Anat., 138(1):153-162.

Badawy, A.B.A.; Ragab, R.S.A and Youssef, H.I. (1982): Histological and biochemical structure of accessory reproductive glands of castrated camel. J. Egypt Vet. Med. Assoc., 42 (3): 113-120.

Badia, E.; Briz, M.D.; Pinart, E.; Sancho, S.; Garcia, N.; Bassols, J.; Pruneda, A.; Bussalleu, E.; Yeste, M.; Casas, I. and Bonet S. (2006): Structural and ultrastructural features of boar bulbourethral glands. Tissue and Cell, 38: 7-18.

Bancroft, J. and Gamble, A. (2008): Theory and Practice of Histological techniques. $6^{\text {th }}$ Ed., Churchill- Livingstone, Edinburgh, London, Melbourne, New York.

Bhosle, N.S.; Shingatgire, R.K. and Kapadnis, P. J. (2006): Comparative histological studies on the prostate gland in uncastrated and castrated cattle. Ind. J. Animal Sci., 76(9): 704-706. 
Bravo, P.W.; Skidmore, J.A. and Zhao, X. X. (2000): Reproductive aspects and storage of semen in Camelidae. Animal Reproduction Science, 62: 173-193.

El-Alfy, M.; Pelletier, G.; Hermo, L.S. and Labrie, F. (2000): Unique features of the basal cells of human prostate epithelium. Micros. Res. Techn., 51(5): 436 - 446.

El-Wishy, A.B.; Mubarak, A.M. and Fouad, S.M. (1972): The accessory genital organs of one humped camel (camelus dromedarius). Anatornischer Anzeiger 131: 1-12. Emara, S.A. (1994): Histological and histochemical studies on the seasonal changes of male accessory genital glands of the buffalo. Ph.D Thesis, Fac. Vet. Med., Moshtohor Zagazig Univ. (Benha), Egypt.

Hafez, E.S.E. (1993): Reproduction in farm animals, $6^{\text {th }}$ Ed. Lea and Febiger, Philadelphia, U.S.A.

Hayat, M. (1986):Basic technique for transmission electron microscope. $2^{\text {nd }}$ Ed. Academic Press, Baltimore.

Mao, P. and Angrist, A. (1966): The fine structure of the basal cell of human prostate. Lab. Invest., New York, 15: 1782-1799.

Marei, H.E.S.; El-Habback, H.A. and Abou-Esa, K.F. (2004): Histology, fine structure and carbohydrate histochemistry of the epithelium of the accessory genital glands of Egyptian baladi goat. Vet. Med. J., Giza, 52 (2): 165-182.

Mosallam, El-S.M. (1981):Histological and histochemical studies of male accessory genital glands of the adult camel (camelus dromedarius ) in the different season of the year .Ph. D. Thesis, Fac. Vet. Med., Cairo Univ., Egypt

Moussa, M.H.G.; Badawy, A.B.A.; Kandil, M.H. and Shahin, Y. M. (1983):Histological and histochemical studies of the accessory genital glands of buffalo- bull (Bubalis bubalis). Anat. Anz., 153:429-439.

Nasr, M.T. and Moustafa, I.A. (1988): Morphohistological and histochemical studies on the prostate gland of the camel (camelus dromedarius) during different ages. J. Egypt Vet. Med. Assoc., 48 (3): 317 -331.

Nicaise, M.; Lauwers, $H$. and Simoens, $P$. (1991):Morphological study of the development of the disseminate prostate in the intact and castrated male pigs aged two to six months. Acta. Anat., 141:335-347.

Reynolds, E.S. (1963): The use of lead citrate at high $\mathrm{pH}$ as an electron opaque stain in electron microscopy. J. Cell Biol., 17:208-212.

Robert, K.A.; Faulkner, L. C. and Abdel-Raouf, M. (1969): Glands associated with the urethra of the bull. Am. J. of Vet. Res., 30: 963-679.
Ruba, O.; Falah, Sh. and Mousa, D. (2005): Castration induced changes in dog prostate gland associated with diminished activin and activin receptor expression. Life Sci., 77:2752-2759.

Sakairi, A.; Tsukise, A.; Nara, T.; Habata, I. and Yamada, K. (2003):Histochemical analysis of glycoconjugates in the disseminate prostate gland of the wild boar (Sus scrofa riukiuanus). Acta. Histochem. Cytochem., 36 (5):455-463.

Sharmanov, T. Sh., Kadyrova, R.Kh., Shlygina, O.E. and Zhaksylykova, R.D.(1978): Changes in the indicators of racioactive isotope studies of the liver of patients with chronic hepatitis during treatment with whole camels' and mares' milk. Voprosy Pitaniya, 1: 9-13.

Silvana, G.P.C.; Cristiani, Z.; Maira, G.R. and Taboga, R.S. (2006): Biological behavior of the Gerbil ventral prostate in three Phases of postnatal development. Anat. Rec., 288(A):723-738.

Skidmore, L. and Adams, G.P. (2000): Anatomy of the Camel Reproductive Tract. The Camel Reproduction Centre, Dubai, United Arab Emirates.

Sudhakar, L.S. (2005): Histomorphology of accessory genital glands of yak - a preliminary study. Ind. J. Animal Sci., 75(8): 943-944.

Sylwia, S.G.; Maria, L.; Wojciech, G. and Marcin, W. (2006): Morphology of the epithelial cells and expression of androgen receptor in rat prostate dorsal lobe in experimental hyperprolactinemia. Folia. Histoch. Cyto., 44(1): 25-30.

Timms, B.G.; Chandler, J.A. and Sinowatz, F. (1976): The ultrastructure of basal cells of rat and dog prostate. Cell and Tissue Res., 173(4).

Wellerson, R. S.; Daniel, E. S.; Silvana, G.P.; Campos, L. S.; Corradi, P. S.; Leite, V. and Taboga, S. (2008): Oestrogen supplementation following castration promotes stromal remodelling and histopathological alterations in the Mongolian gerbil ventral prostate. Int. J. Exper. Pathol., 89( 1):25-37.

White, I. Ca. (1974): Mammalian semen. In; reproduction in farm animals. cited by Hafez (1974).

Yao, T.S. and Orson, N. E. (1954):Postnatal growth and histological development of the reproductive organs of male goat. Am. J. Anat., 95:401-410.

Zaghloul, A.H.; Nafady, A. and Shehata, S. H. (1988): Seasonal changes in the morphology and histology of the genital organs of one humped camel. Assuit Vet. Med. J., $20(40)$.

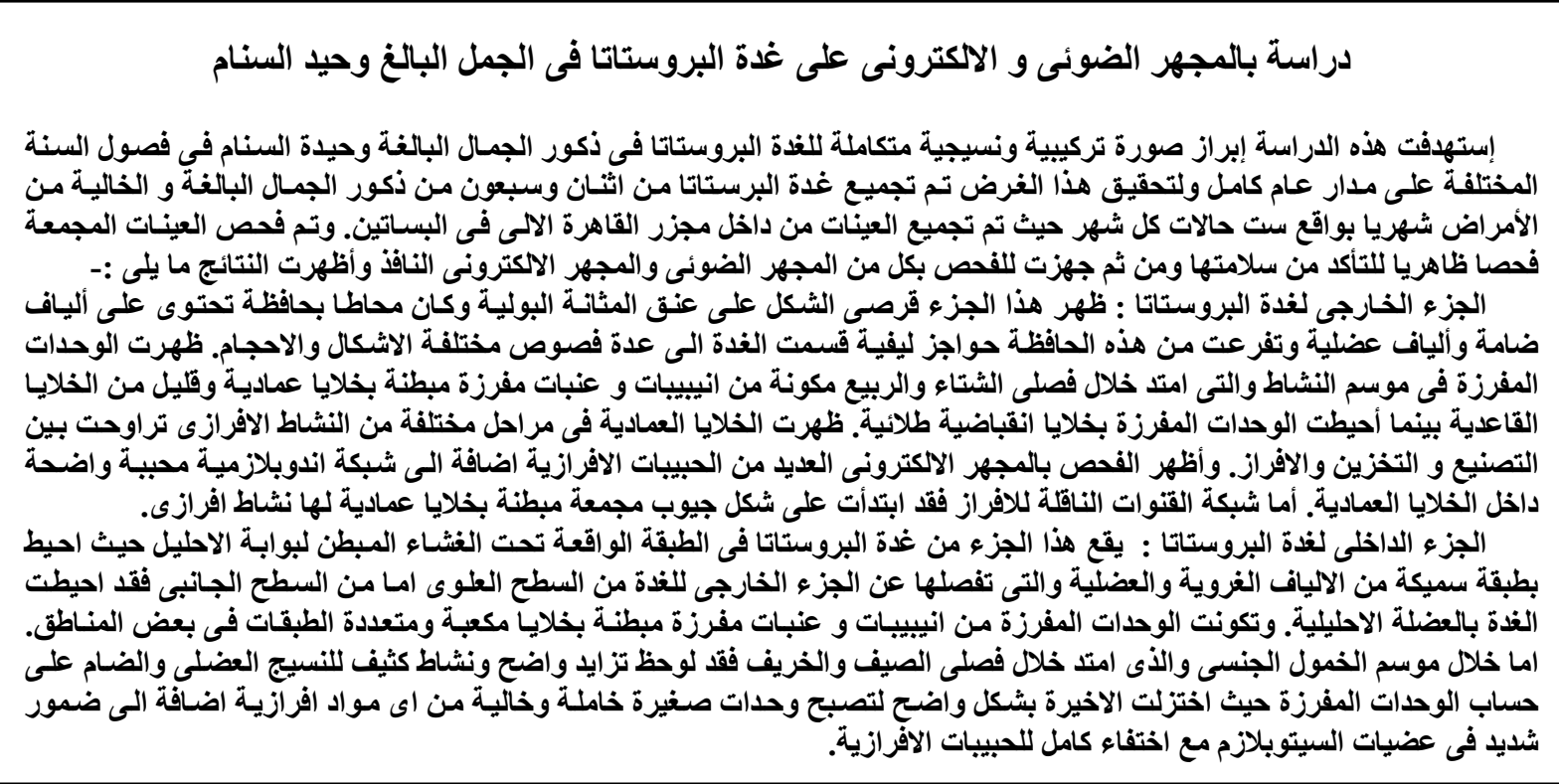

